\title{
Delineating well-head protection areas under conditions of hydrogeological uncertainty. A case-study application in northern Greece
}

\author{
Nicolaos Theodossiou $^{1} \cdot$ Eleni Fotopoulou ${ }^{1}$
}

Received: 17 January 2015 / Accepted: 17 July 2015 / Published online: 5 August 2015

(C) Springer International Publishing Switzerland 2015

\begin{abstract}
The delineation of well-head protection areas, especially for water supply wells, is of most importance in ensuring water quality. The areas delineated under this concept must be large enough to ensure that no pollutants will end-up and be pumped-off by abstraction wells but at the same time, small enough to minimize the social and economic cost of applying restriction measures to nearby land owners. The whole concept of applying well-head protection areas is based on the recognition of the hydrogeological parameters of the aquifer. The fact that these parameters are, by nature, characterized by uncertainty makes the whole application very difficult. In this paper, the delineation of well-head protection areas is simulated through a mathematical model and the methodology is applied on the aquifer of Moudania in Chalkidiki, taking into consideration a number of equally probable realizations of the geological structure of the aquifer. This aquifer is characterized by the spatial variability of its hydrogeological parameters, making the introduction of uncertainty in its simulation, an absolute necessity.
\end{abstract}

Keywords Groundwater - Well-head protection areas · Uncertainty $\cdot$ Water resources management $\cdot$ Hydrogeological parameters

\section{Introduction}

The problem of identifying, or at least estimating, the geological structure of groundwater aquifers and their respective hydrogeological parameters is one of the main obstacles in understanding their functional characteristics and in applying groundwater simulation and management models. A variety of techniques and procedures have been presented in literature, emphasizing on the characterization of aquifer structure heterogeneity by using methods based

Nicolaos Theodossiou

niktheod@civil.auth.gr

Eleni Fotopoulou

lefoto@civil.auth.gr

1 Division of Hydraulics and Environmental Engineering, Department of Civil Engineering, Aristotle University of Thessaloniki, 54124 Thessaloniki, Greece 
on geostatistics. Proce et al. (2004) presented an extensive review of the methods used to characterize and model sedimentary architecture in aquifers, by dividing the methods into two groups. The former group includes methods that statistically characterize the architecture using lithologic data from borehole logs, a method known as statistical stratigraphy. The latter group includes methods used to model correlation and to generate realizations of the aquifer's architecture suitable for use in flow and transport models. The transition probability based geo-statistical models (Carle et al. 1998; Carle 1999; Bohling and Dubois 2003; Papapetrou and Theodossiou 2010; Fotopoulou 2014) used in this paper, belongs to the latter group.

The transition probability/Markov approach of indicator geostatistics is a relatively new method, compared to the traditional ones, for representing heterogeneity in 3-D soil stratigraphy. Steven F. Carle and other researchers (Carle et al. 1998; Carle 1999; Weissmann et al. 1999) have demonstrated that this approach has some unique advantages over traditional indicator methods like stochastic Gaussian fields based on autocorrelations or variograms (Deutsch and Journel 1992). The basic advantage in addition to indicator kriging methods, is that the conditional probabilities in Markov chain models are interpreted geologically much easier. Geological observations and principles (e.g., fining up/down sequences and juxtapositional tendencies) can be directly implemented in the transition probability matrix. Carle (1999) has developed a software package called T-PROGS that operates on the basis of transition probabilities. The stochastic simulation procedure involves generating alternate, equally probable, high resolution models of the spatial distribution of aquifer zones.

The field of well-head protection areas has been thoroughly investigated due to its scientific interest and its practical application. In a work presented by the United States Environmental Protection Agency (EPA 1998), an analytical literature review of the methods used for the delineation of well-head protection areas is documented. This analysis includes the presentation of the theoretical background and a number of case-study applications. It also includes a presentation of analytical and numerical models used as well as aspects concerning land use, mapping and G.I.S.

Levy and Ludy (2000) used the three-point Gauss-Hermite quadrature formula in order to estimate the impact of uncertainties associated with six model parameters, in the delineation of well-head protection areas of two municipal wells in Ohio. Feyen et al. (2001) presented a stochastic approach for the delineation of capture zones. This stochastic approach is based on modelling the hydraulic conductivity coefficient as a random space function allowing for the uncertainty that stems from the imperfect knowledge of the parameters of the correlation structure. Kailash (2003) presented the results of a parametric analysis conducted to evaluate the effect of data uncertainty on well-head protection area (WHPA) delineation.

In order to overcome one of the most common problems in the delineation of wellhead protection areas, that of ignoring or simplifying the processes outside the saturated groundwater zone and of neglecting dynamic and transient effects, Graham et al. (2005) applied the watershed modelling tool MIKE-SHE, performing a sensitivity analysis over 16 of the most sensitive parameters using the Monte-Carlo approach, in order to estimate the well-head protection areas under conditions of uncertainty. Esling et al. (2008) proposed a systematic approach to calibrate a numerical flow model to regional topography and then applied a matrix of plausible recharge to hydraulic conductivity ratios to investigate the impact on the size and shape of capture (and protection) zones. Their procedure results to several possible capture zones and, as in this paper, they propose the use of their composite which is likely to contain the actual capture zone. 


\section{Description of the study area}

The town of Moudania is located in the Nea Propontida municipality, in the western part of the prefecture of Chalkidiki, a peninsula with a distinct shape in northern Greece.

Geomorphologicaly, it can be separated in two different parts as a result of the tectonic activity: the central and northeastern mountain area section with steep topography, and the southwestern area of low hilly topography, which is mainly of flat extent.

The under study basin, the watershed and the underlying aquifer of Moudania extend to an area of $127 \mathrm{~km}^{2}$ (Latinopoulos 2002). The prevalent form of hydrographical network is basically straight and parallel watercourses in the southern part of the basin and watercourses with a dendritic structure in the northern part (Fig. 1).

The aquifer is surrounded by a no-flow boundary except for the south-western border where, along the seashore, the boundary is considered as a constant head one. The aquifer is replenished only through rainfall. The streams have only seasonal flow, basically after rainfall events, and their contribution in the replenishment of the aquifer is not considered to be significant. Rainfall data are recorded, collected and analysed by the nearby meteorological station of Agios Mamas (Latinopoulos 2002).

As far as the geology of the area is concerned, the "formation of Moudania" (Latinopoulos 2002; Xefteris 2000) is dominated by red clays, which cover most of the area and form a

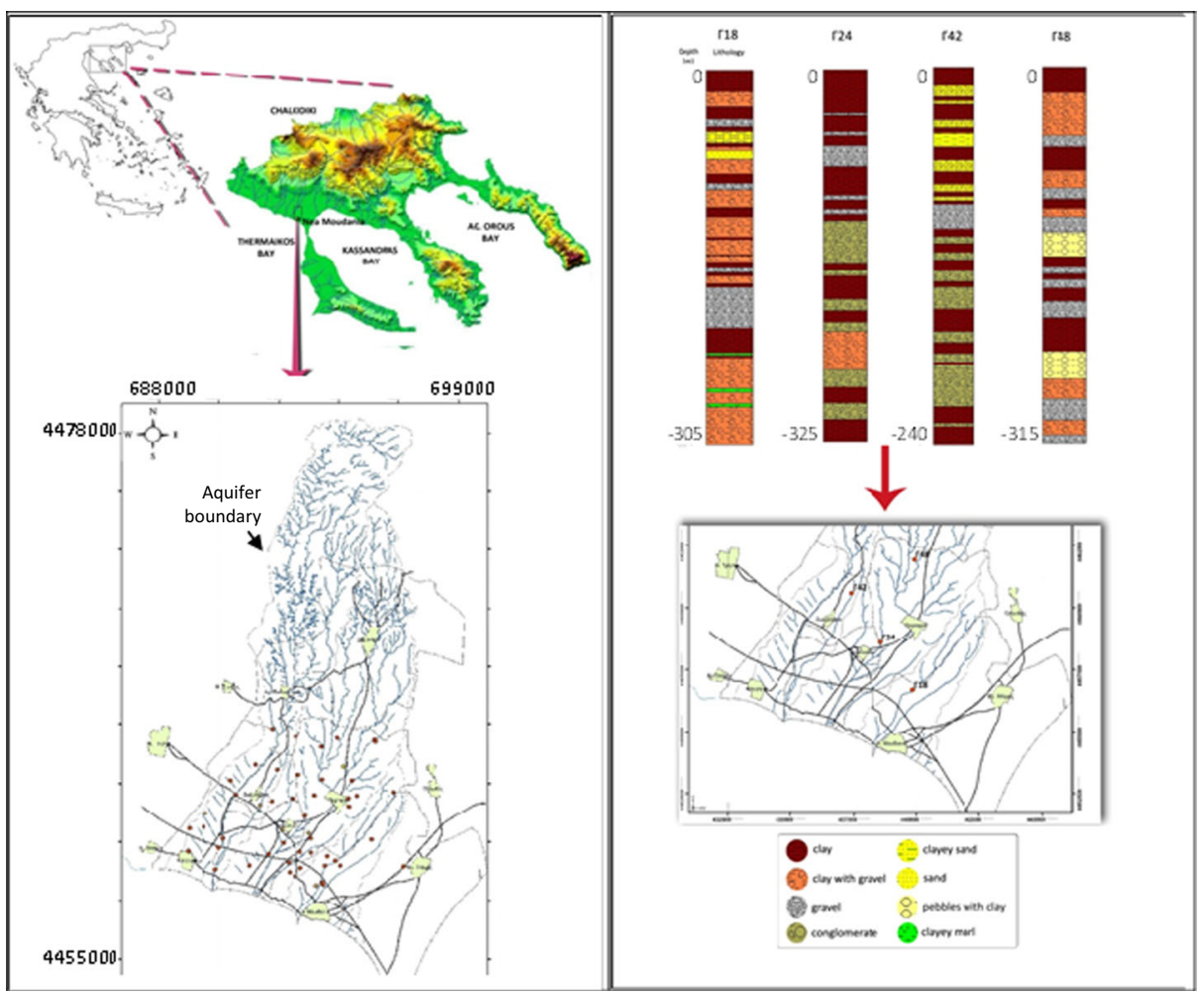

Fig. 1 The Moudania watershed in Chalkidiki, Northern Greece (left) and four typical geological cross-section (right) 
smooth surface. The formation of Moudania includes a large volume of terra rosa, constituted by alternations of gravel, sandstone, pebbles and sandy-silty clay. The coarse material extents within the clay lens with variable thickness. In some parts there is great diversity in the structure of the material, which is probably due to different deposition phases.

According to the prevailing conditions, the formations can be divided in two main categories: those with good ground water capacity such as sandstones, gravels, pebbles, and those that are practically considered as rocks with no ground water capacity such as schistose and gneisses. According to the lithological structure of the boreholes (Latinopoulos 2002), the under study aquifer shows intense horizontal and vertical material heterogeneity as shown in a representative section of a typical borehole presented in Fig. 1.

\section{Stochastic simulation of the aquifer's geological structure}

In order to find the spatial distribution of the soil materials that form the aquifer, incorporating the aspect of uncertainty, the stochastic simulation was performed using the T-Progs module (Carle 1999). T-Progs is a software package that performs transition probability geostatistics to generate multiple equally probable models of aquifer heterogeneity, all of which can be conditioned to borehole data. T-Progs is generally used in a stochastic modelling approach with the ModFlow 2000 model (Harbaugh et al. 2000). Both ModFlow 2000 and T-Progs are included in the Groundwater Modelling System - GMS (2012) software. The concept is to use all the available data, regarding soil materials, from the cross-sections of the boreholes in order to construct models of the geological structure of the aquifer. In this way, this very valuable information is exhaustively exploited in order to maximize the understanding of the aquifer. These data include:

- The geological formations recorded in each borehole cross-section

- The order (top, middle or bottom of the aquifer) in which these formations are found

- The statistical significance of the sequence of appearance of each formation in each borehole cross-section

- The statistical significance of appearance of each formation in neighbouring boreholes

The position where each borehole with available geological cross-section is located, is demonstrated with red dots in the left-hand side part of Fig. 1, while their connections are represented in a three-dimensional diagram (Fig. 2).

To implement T-Progs in GMS, the site's hydrogeology should be simplified into a maximum of four materials. This software limitation was imposed to keep the data processing and userinterface at a reasonably simple, and thus feasible, level. For this reason, the geological formations were grouped to three main categories according to the level of hydraulic conductivity (Papapetrou and Theodossiou 2010). For instance, the geological formations with fine texture such as clay, clayey silt, clayey marl and marl were grouped as material 1 and named as "clay". On the other hand, the formations with coarse texture such as gravel, pebble, conglomerate, sand, sandy gravel and sandstone were grouped as material 4 and are named as "gravel". Material types 2 or "clay-gravel" and 3 "sand-gravel" categories contain mixed texture of the previous formation types such as clay with gravel, pebbles with clay, clayey sand and marlstone.

These models will then be used in order to simulate the function of the aquifer including the delineation of capture zones, and thus, the well-head protection area of a selected pumping 


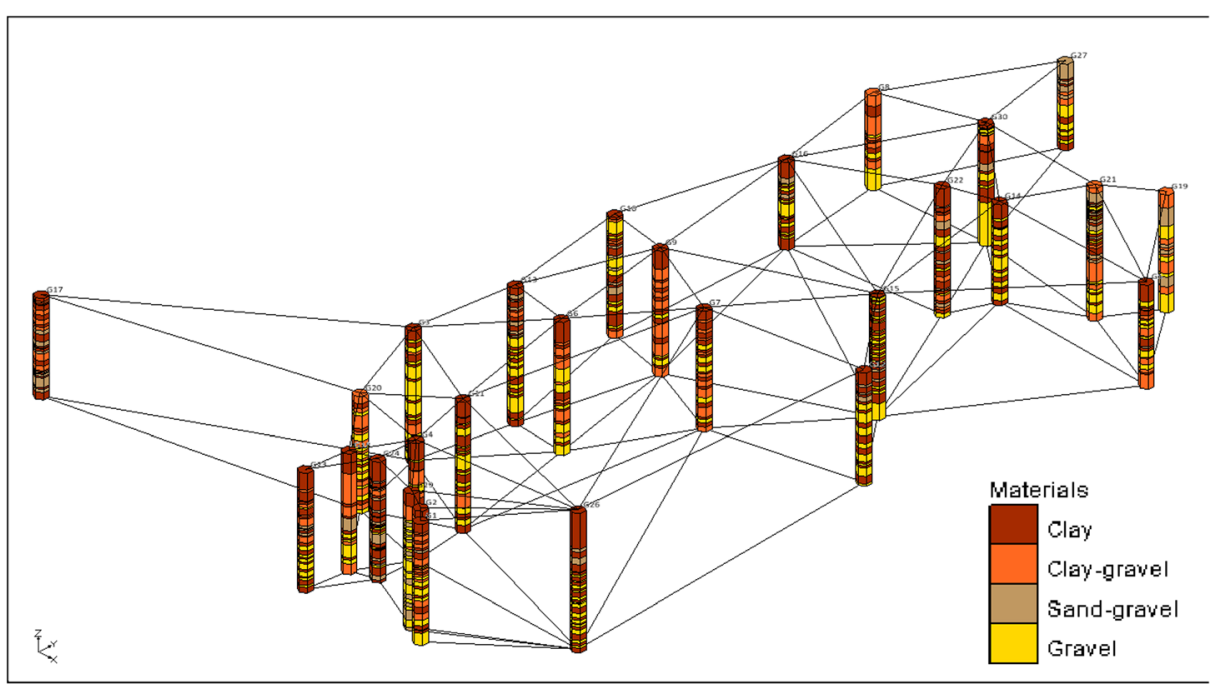

Fig. 2 A three-dimensionsal representation of the connections and relative positions of boreholes with geological data

well. It is obvious that since the available borehole data are never enough, this procedure results in a stochastic approach of the structure of the aquifer. The less the available data, or the smaller their relevance, the higher the uncertainty introduced. T-Progs is used to solve two significant statistical problems:

- The first one is to define the transition probability data for each geological material recorded in the cross-sections of the boreholes. This is achieved by computing a set of transition probability curves as a function of lag distance for each material for a given sampling interval.

- The second is to generate the multiple material sets during the simulation stage. This is achieved by applying Markov Chains to formulate the equations used to estimate these material sets. The objective of this stage of the analysis is to fit the Markov Chain curves as accurately as possible to the measured transition probability curves. This process is similar to fitting a model variogram to an experimental variogram in a kriging exercise.

More details on these specific applications over the Moudania aquifer can be found in relevant publications (Theodossiou and Fotopoulou 2009; Papapetrou and Theodossiou 2010, 2012; Fotopoulou 2014). Figure 3 demonstrates a three-dimensional representation of the aquifer's geological structure under conditions of uncertainty as produced by the application of the T-Progs module. This is one of many equally probable realizations of the aquifer's structure, with each colour representing a different soil material. The geological structure in some of the cells has a significant degree of confidence due to the existence of actual measurements. Other cells though are characterized by small, medium or even large degree of uncertainty due to the lack of measurements or due to the inconsistency of the surrounding data. The degree of uncertainty is related to the distance from existing measurements. The larger the distance to measurement sites the larger the geological uncertainty. 


\section{Delineation of well-head protection areas}

A well-head protection area is defined as the area that needs to be protected (by imposing restrictions on the activities that can be developed) so that no pollutants of high concentrations can reach the pumping well. Respectively, a capture zone (or contribution zone) defines the surface or subsurface surrounding area, which includes water and pollutants that will finally end up in a certain time period and be abstracted by the well.

The method used in this paper for the estimation of the well-head protection area is the "particle tracking technique" using the time criterion. According to this criterion, the well-head protection area is determined by considering the time required for the pollutant to reach the well. The particle tracks, according to the reverse pathline method, derive from the solution of the following system of differential equations (Shafer 1987):

$$
\mathrm{f}(\mathrm{x}, \mathrm{y})=(\mathrm{dx} / \mathrm{dt})=\mathrm{v}_{\mathrm{x}}(\mathrm{x}, \mathrm{y}), \mathrm{g}(\mathrm{x}, \mathrm{y})=(\mathrm{dy} / \mathrm{dt})=\mathrm{v}_{\mathrm{y}}(\mathrm{x}, \mathrm{y})
$$

where

$$
\mathrm{v}_{\mathrm{x}}(\mathrm{x}, \mathrm{y})=\mathrm{q}_{\mathrm{x}}(\mathrm{x}, \mathrm{y}) / \mathrm{n}_{\mathrm{e}}(\mathrm{x}, \mathrm{y}), \mathrm{v}_{\mathrm{y}}(\mathrm{x}, \mathrm{y})=\mathrm{q}_{\mathrm{y}}(\mathrm{x}, \mathrm{y}) / \mathrm{n}_{\mathrm{e}}(\mathrm{x}, \mathrm{y})
$$

and

$$
\mathrm{q}_{\mathrm{x}}=-\mathrm{K}_{\mathrm{x}}(\mathrm{x}, \mathrm{y}) \frac{\partial \mathrm{h}(\mathrm{x}, \mathrm{y})}{\partial \mathrm{x}} \quad \mathrm{q}_{\mathrm{y}}=-\mathrm{K}_{\mathrm{y}}(\mathrm{x}, \mathrm{y}) \frac{\partial \mathrm{h}(\mathrm{x}, \mathrm{y})}{\partial \mathrm{y}}
$$

where $\mathrm{q}_{\mathrm{x}}, \mathrm{q}_{\mathrm{y}}$ are the Darcy velocities on the $\mathrm{x}$ and $\mathrm{y}$ axes in a two-dimensional aquifer, $\mathrm{K}_{\mathrm{x}}, \mathrm{K}_{\mathrm{y}}$ are the hydraulic conductivity coefficients on the $\mathrm{x}$ and $\mathrm{y}$ axes, respectively, $\mathrm{h}(\mathrm{x}, \mathrm{y})$ is the hydraulic head and $\mathrm{n}_{\mathrm{e}}(\mathrm{x}, \mathrm{y})$ is the effective porosity.

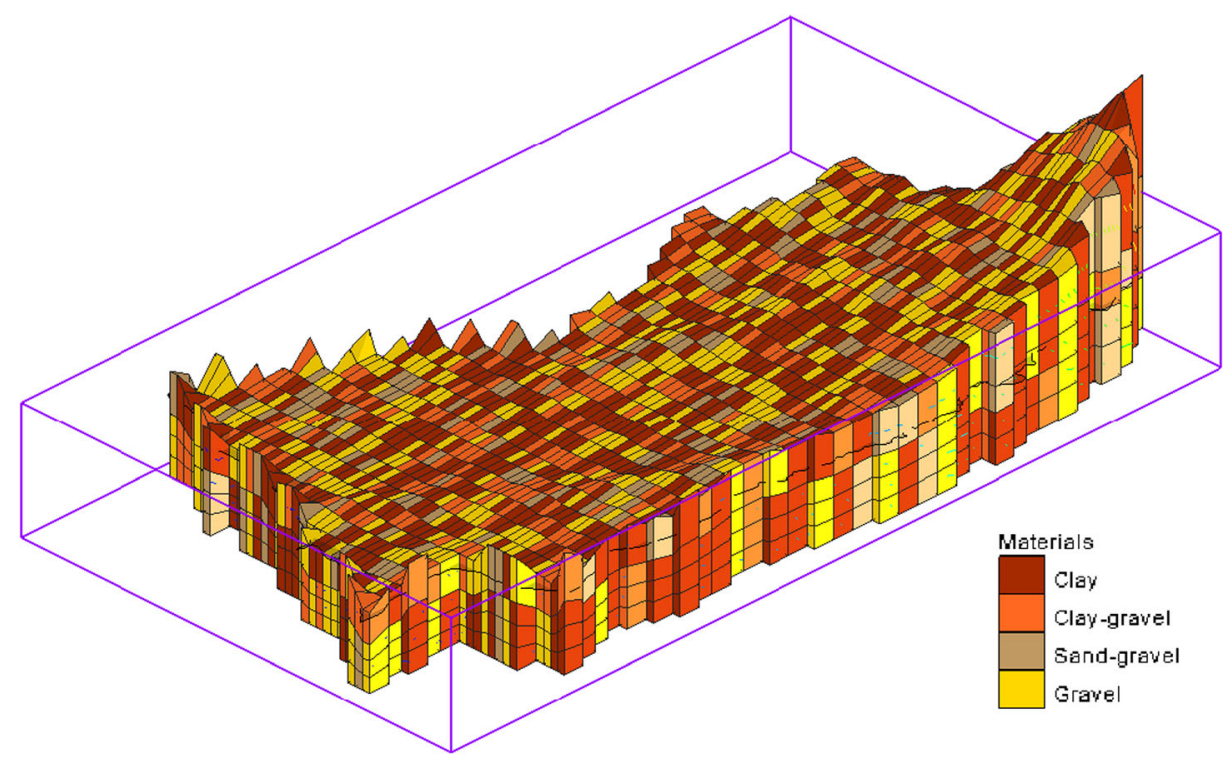

Fig. 3 A three-dimensional representation of the aquifer structure according to one of the material distribution realizations investigated 
The pathline is determined as $\mathrm{s}(\mathrm{t})=[\mathrm{x}(\mathrm{t}), \mathrm{y}(\mathrm{t})]$. Thus, the successive positions of the points of a pathline are $\mathrm{s}_{\mathrm{n}}=[\mathrm{x}(\mathrm{n}), \mathrm{y}(\mathrm{n})], \mathrm{s}_{\mathrm{n}+1}=[\mathrm{x}(n+1), \mathrm{y}(n+1)]$ etc.

For the solution of the problem, the MODPATH module was applied. MODPATH is a particle tracking code that is used in conjunction with MODFLOW. Both models are incorporated in the GMS software package.

\section{The application for the stochastic delineation of well-head protection areas}

In the present study, in order to achieve the delineation of the well-head protection areas taking into consideration the lack of sufficient information concerning the geological structure of the aquifer and the fact that this is a highly heterogenic one, the two techniques presented above were combined. The proposed methodology aims at the recognition of the impact of the uncertainties introduced by the geological structure of an aquifer. There is also a number of parameters that dynamically influence flow as well, such as pumping rate from the under investigation wells as well as from their surrounding ones, rainfall variations, climate changes, land-use (and thus water demand) changes, dispersion, diffusion etc. The purpose of the analysis presented in this paper is not to cover all potential parameters that define well-head protection areas, but to emphasize on the impacts from the geological structure uncertainty in order to isolate and more clearly demonstrate the necessity to analyze geological data in the best possible way.

First of all, the T-Progs module was applied. Using geological data from a number of 30 boreholes scattered over the area of the aquifer (Fig. 2), T-Progs, using the methodology briefly described above (estimation of the transition probability for each geological material, application of Markov Chains technique and estimation of the equations that provide the optimal approach to the Markov Chain curves), was applied in order to produce a number of equally probable realizations of the geological structure of the aquifer.

Twenty different realizations of the geological structure of the aquifer were produced as a result of the application of the above described methodology (Fotopoulou 2014). The main characteristic of these realizations is that, according to the Markov chains analysis, they are equally probable.

The more complex the original observations of the geological structure of the aquifer (as derived from the 30 boreholes), the more complex and non-similar are the realizations derived from the application of T-Progs. A similar variation can also be observed along the vertical axis of the mathematical model simulation of the aquifer.

Using these realizations, one at a time, and applying them as input data describing the geological formation of the aquifer to the GMS software, both the ModFlow and the ModPath modules were executed in order to define the flow field of the aquifer, through ModFlow, and the capture zones, through the reverse pathline option of ModPath. Through this procedure, the well-head protection areas of three newly constructed wells destined for supplying water for domestic use were estimated. The well-head protection areas of 1, 2, 5 and 10 years for the three new pumping wells corresponding to the respective geological structure realizations of the aquifer, were recorded. Of course, the larger the time period, the larger the respective area. Thus, the smaller area represents the 1 year well-head protection area, and the larger, the 10 years well-head protection area, with the other two, 2 and 5 years, lying in between. It is noted that a 1 year capture zone means that water currently included in these captures zones will end up within the time period of 1 year, and be abstracted by the respective well. The 


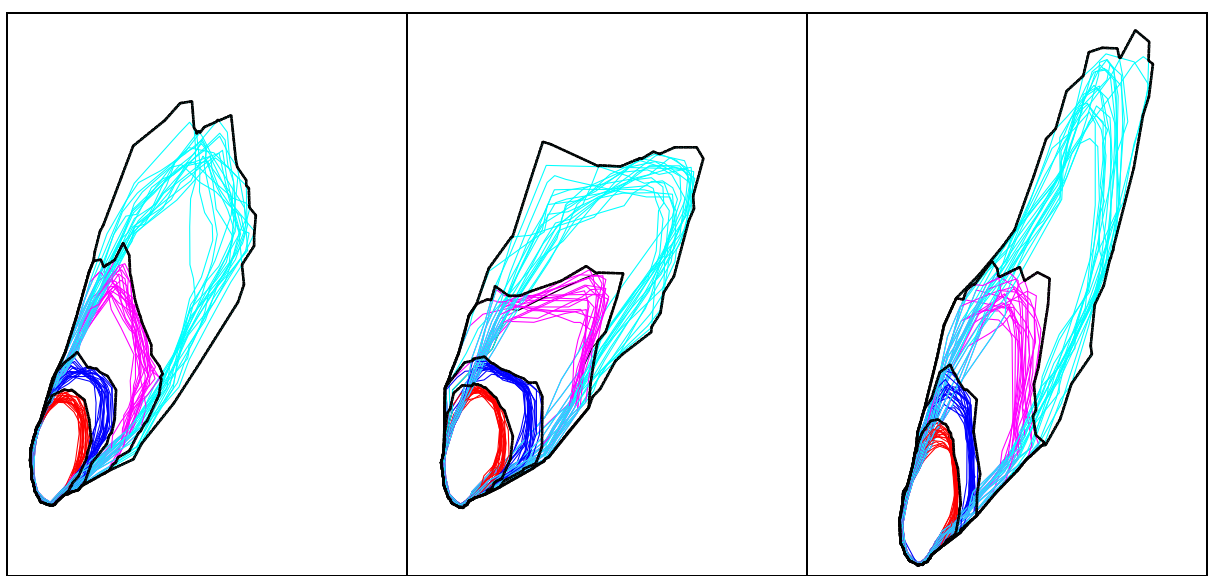

Fig. 4 Synthetic diagrams of 1, 2, 5 and 10 year well-head protection areas for the three wells and overall wellhead protection areas (thick lines)

selection of these specific time periods $(1,2,5$ and 10 years) does not constitute a general approach. These time periods depend on a variety of parameters, including the hydrogeological characteristics of the aquifer, the type of activities, and the risk and hazard they introduce to the groundwater resources and many others. The time periods used in this study cover both immediate pollution events and long-term ones.

The dimensions of the discretization grid are $183 \times 492 \times 70 \mathrm{~m}$ (representing $\mathrm{x}, \mathrm{y}$ and $\mathrm{z}$ dimensions). The pumping rate assigned to the abstraction wells, is considered as $30 \mathrm{~m}^{3} / \mathrm{h}$, which is the actual field pumping rate of these wells, while the mean hydraulic conductivity coefficient of the aquifer is, according to the results of pumping tests performed in the area, $1.0 \mathrm{~m} / \mathrm{d}$.

The differences between these pictures are a result of the different geological structure realizations on which they are based on. The pictures focus on a small part of the aquifer surrounding the pumping wells, in order to provide a more clear view of the results.

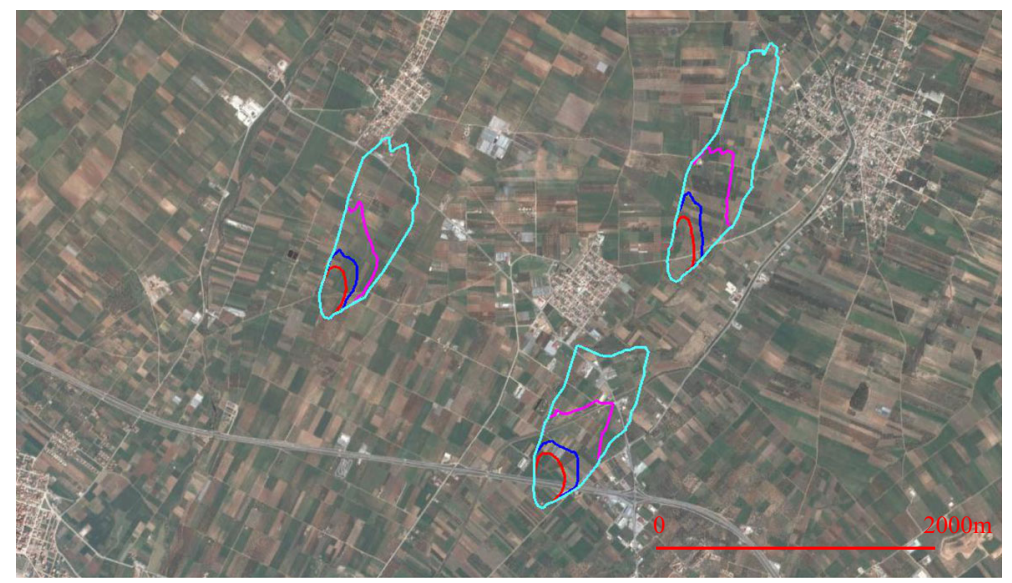

Fig. 5 Field application of the resulting well-head protection areas in the study area (picture from Google Earth) 
Performing the same methodological procedure for each one of the twenty equally probable realizations of the aquifer's geological structure, for each one of the three pumping wells one can result to the delineation of each one of the four time limited well-head protection areas. The results of this procedure are presented in Fig. 4. The three diagrams presented in the first line of Fig. 4, present all the well-head protection areas produced through the application of the proposed methodology. Respectively, the three diagrams presented in the thicker line of Fig. 4 , present the final delineation of the well-head protection areas, through lines that cover all expected possible, and equally probable, protection areas. By applying these lines, one can ensure that he is on the safe side in protecting the water abstracted by the pumping wells.

Finally, Fig. 5 presents the application of the results of the proposed procedure in the field. For this purpose, a picture from Google Earth is used as a background image on which the delineated well-head protection areas are imposed. Thus, one can identify in the field the areas that need to be protected, in order to ensure the good quality of the water abstracted by the pumping wells. Using Fig. 5, one can also identify activities, practices or installations that could potentially pollute the underlying groundwater and, depending on the location of these potential pollutants in relation to the respective time-identified well-head protection areas, take the necessary measures.

\section{Conclusions}

It is obvious from the above that, the very important issue of protecting the quality of groundwater water abstracted by pumping wells, is a very complex one. The successful application of well-head protection areas, with all the impacts they impose (e.g., restriction measures on private or public property with, sometimes, serious socio-economic impacts), must be handled considering the uncertainty of the hydrogeological characteristics of the aquifer. This kind of uncertainty, which is a natural characteristic of most aquifer systems, can alter significantly the delineated areas.

The results presented in Fig. 5 are a typical example of the above comment. Let us consider, for example, the case where the water managers estimate the well-head protection area according to the realization presented in the last picture of Fig. 5. If the actual geological structure of the aquifer in more close to the first realization, then it is obvious that if the aquifer is polluted in an unprotected part of the area presented in one of these figures, then the water abstracted by the well, after a few months, will be unsuitable for domestic use.

Acknowledgments An initial version of this work has been presented in the 12th International Conference on Protection and Restoration of the Environment, Skiathos Island, Greece, June 29 to July 3, 2014.

\section{References}

Bohling GC, Dubois MK (2003) An integrated application of neural network and markov chain techniques to prediction of lithofacies from well logs. Kansas Geol Survey Open File Report 2003-50, 6 p

Carle SF (1999) T-PROGS: transition probability geostatistical software. Version 2.1. University of California, Davis Carle SF, Labolle EM, Weissmann GS, Brocklin DV, Fogg GE (1998) Conditional simulation of hydrofacies architecture: a transition probability/Markov approach. In: Fraser GS, Davis JM (eds) Hydrogeologic models of sedimentary aquifers, concepts in Hydrogeology and Environment Geology, Tulsa, vol 1. pp 147-170 
Deutsch CV, Journel AG (1992) GSLIB, Geostatistics software library and user's guide. Oxford University Press, New York, $340 \mathrm{p}$

Environmental Protection Agency (1998) Literature review of methods for delineating wellhead protection areas, U.S. E.P.A. 816-R-98-021, Office of water

Esling SP, Keller JE, Miller KJ (2008) Reducing capture zone uncertainty with a systematic sensitivity analysis. Ground Water 46(4):570-578

Feyen L, Beven KH, De Smedt F, Frer J (2001) Stochastic capture zone delineation within the generalized likelihood uncertainty estimation methodology: conditioning on head observations. Water Resour Res 37(3): 625-638

Fotopoulou E (2014) Investigation of the application of well-head protection delineation practices under conditions of uncertainty, Ph.D. thesis. Department of Civil Engineering, Thessaloniki

Graham DN, Butts MB, Madsen H, Lonborg MJ (2005) Source water protection based on uncertainty of dynamic capture zones using MIKE-SHE, Proc. Of NZHS-IAH-NZSSS Joint Conference "Where waters meet", Auckland, New Zealand

Groundwater Modelling System (2012) GMS 8.2 Software, Retrieved from www.aquaveo.com/gms. Last accessed 20 Feb 2014

Harbaugh AW, Banta ER, Hill MC, McDonald MG (2000) MODFLOW-2000, the U.S. Geological Survey modular ground-water model - User guide to modularization concepts and the Ground-Water Flow Process: U.S. Geological Survey Open-File Report 00-92, $121 \mathrm{p}$

Kailash B (2003) Uncertainty in wellhead protection area delineation due to uncertainty in aquifer parameter values. J Hydrol 149(1):1-8

Latinopoulos P (2002) Development of water resources management plan for water supply and irrigation for the municipality of Moudania, Research Project. Department of Civil Engineering, Aristotle University of Thessaloniki, Thessaloniki

Levy J, Ludy EE (2000) Uncertainty quantification for delineation of wellhead protection areas using the GaussHermite quadrature approach. Ground Water 38(1):63-75

Papapetrou M, Theodossiou N (2010) Stochastic analysis of the geological structure of groundwater aquifers, International Conference on Protection and Restoration of the Environment X, Corfu

Papapetrou M, Theodossiou N (2012) A methodology for the stochastic approach of the geological structure of groundwater aquifers. Application to an aquifer in northern Greece, International Conference on Protection and Restoration of the Environment XI, pp 316-325, Thessaloniki

Proce C, Ritzi R, Dominic D, Dai Z (2004) Modeling multiscale heterogeneity and aquifer interconnectivity. Ground Water 42:658-670

Shafer JM (1987) Reverse pathline calculation of time-related capture zones in non-uniform flow. Ground Water 25:283-289

Theodossiou N, Fotopoulou E (2009) Delineation of well head protection areas using stochastic analysis approach, 11th International Conference on Environmental Science and Technology, 1440-1447, Chania

Weissmann GS, Carle SF, Fogg GE (1999) Three-dimensional hydrofacies modeling based on soil surveys and transition probability geostatistics. Water Resour Res 35:1761-1770

Xefteris A (2000) Investigation of groundwater resources quality degradation in the basin of Kalamaria with emphasis on nitrate pollution, Ph.D. thesis. Department of Civil Engineering, Thessaloniki 